\title{
Evidence mapping and quality assessment of systematic reviews on therapeutic interventions for oral cancer
}

This article was published in the following Dove Press journal: Cancer Management and Research

\author{
Meisser Madera Anaya ${ }^{1-3}$ \\ Juan Victor Ariel Franco 4 \\ Mónica Ballesteros ${ }^{2}$ \\ Ivan Solà ${ }^{2,3}$ \\ Gerard Urrútia Cuchí2,3 \\ Xavier Bonfill Cosp $p^{2,3,5}$ \\ 'Department of Research, Faculty of \\ Dentistry, University of Cartagena, \\ Cartagena, Colombia; ' 2 lberoamerican \\ Cochrane Centre, Institute of \\ Biomedical Research Sant Pau \\ (IIB Sant Pau), Barcelona, Spain; \\ ${ }^{3}$ Department of Public Health and \\ Clinical Epidemiology, Hospital de \\ la Santa Creu i Sant Pau, Universitat \\ Autònoma de Barcelona, Barcelona, \\ Spain; ${ }^{4}$ Department of Research, \\ Cochrane Argentina, Instituto \\ Universitario Hospital Italiano, \\ Buenos Aires, Argentina; ${ }^{5} \mathrm{CIBER}$ \\ de Epidemiología y Salud Pública \\ (CIBERESP), Barcelona, Spain
}

Purpose: This evidence mapping aims to describe and assess the quality of available evidence in systematic reviews (SRs) on treatments for oral cancer.

Materials and methods: We followed the methodology of Global Evidence Mapping. Searches in MEDLINE, EMBASE, Epistemonikos and The Cochrane Library were conducted to identify SRs on treatments for oral cancer. The methodological quality of SRs was assessed using the Assessing the Methodological Quality of Systematic Reviews-2 tool. We organized the results according to identified Population-Intervention-Comparison-Outcome (PICO) questions and presented the evidence mapping in tables and a bubble plot.

Results: Fifteen SRs met the eligibility criteria, including 118 individual reports, of which $55.1 \%$ were randomized controlled clinical trials. Ten SRs scored "Critically low" methodological quality. We extracted 30 PICOs focusing on interventions such as surgery, radiotherapy, chemotherapy, targeted therapy and immunotherapy; 18 PICOs were for resectable oral cancer, of which 8 were reported as beneficial. There were 12 PICOs for unresectable oral cancer, of which only 2 interventions were reported as beneficial.

Conclusion: There is limited available evidence on treatments for oral cancer. The methodological quality of most included SRs scored "Critically low". The main beneficial treatment reported by authors for patients with resectable oral cancer is surgery alone or in combination with radiotherapy or chemotherapy. Evidence about the benefits of the treatments for unresectable oral cancer is lacking. These findings highlight the need to address future research focused on new treatments and knowledge gaps in this field, and increased efforts are required to improve the methodology quality and reporting process of SRs on treatments for oral cancer.

Keywords: mouth neoplasms, oral carcinoma, buccal tumor, evidence synthesis, evidencebased medicine

\section{Introduction}

Oral cancer is one of the most prevalent cancers worldwide. Oral squamous cell carcinoma is the most common cancer occurring in the mouth, with an estimate of 300,000 new cases globally each year; only in the US, there were around 50,000 new cases expected in 2017. ${ }^{1}$ Oral cancer is posing an ever-increasing threat to global health and represents a growing burden on health services, which is a major problem in some parts of the world, especially in developing countries. Risk factors for oral cancer are frequently associated with lifestyle habits, such as smoking, alcohol abuse, poor nutrition and the use of betel quid. ${ }^{2}$

Unfortunately, the overall prognosis in these patients is low, with a 5-year survival rate of $50 \%$, which has not changed over the last decades despite the advances in oncology treatment. ${ }^{3}$ Locoregionally advanced oral cavity cancers are
Correspondence: Meisser Madera Anaya Iberoamerican Cochrane Centre, Carrer Sant Antoni Maria Claret 167, Pavello 18, Planta 0, CP: 08025, Barcelona, Spain Tel +34 935537808

Emailmmaderaa@unicartagena.edu.co 
aggressive tumors with high probabilities of relapse after definitive treatment with surgery or radiotherapy. Therefore, a multimodal approach, combining surgery and postoperative radiotherapy or chemoradiotherapy, has been suggested. ${ }^{4,5}$

Currently, there is a vast published scientific literature proposing a variety of treatment approaches for oral cancer. This fact may hinder knowing the effectiveness of such therapies and when they should be used. Furthermore, some research may be influenced by conflicts of interest. Thus, a critical analysis and a methodological quality assessment of the available evidence are required. In this sense, one of the options to organize and critically assess published studies is systematic reviews (SRs), which summarize the results of the evidence from health care primary studies in order to answer a specific research question. ${ }^{6}$

Likewise, there are new tools for evidence synthesis, such as evidence mapping, scoping reviews and rapid reviews, which have been developed to help clinicians, patients, researchers and other stakeholders to make evidence-based decisions. ${ }^{7}$ These new options are appropriate to address issues that may be too extensive for an SR. ${ }^{8}$

In 2007, the Global Evidence Mapping (GEM) initiative was established as a collaboration of clinical research and policy stakeholders to provide an overview of existing research about traumatic brain injury and spinal cord injury. ${ }^{9}$ Evidence mapping provides an innovative and visual approach to establish what we know and do not know about the effects of interventions on a thematic area. It can support evidence-informed decision making by facilitating evidence from existing SRs in a user-friendly format. ${ }^{7,10}$

The aim of this evidence mapping is to identify, describe and organize the current available evidence in SRs regarding therapeutic interventions for oral cancer. This approach purposes to determine the clinical questions assessed in the scientific literature and the corresponding quality of the supporting evidence, as well as to give general information about their claimed effectiveness. This information shall facilitate detecting research gaps and help stakeholders in the decision-making process.

\section{Materials and methods Study design}

This evidence mapping adhered to the PRISMA-Extension for Scoping Reviews. ${ }^{11}$ It was carried out in accordance with the methodology proposed by GEM, ${ }^{9}$ adding some previously suggested tasks. ${ }^{12}$ All methods were specified a priori in a protocol (available on request).

\section{Eligibility criteria}

We included SRs published any year, with or without meta-analysis, assessing any therapeutic interventions in patients diagnosed with oral cavity cancer defined by the ICD for Oncology ${ }^{13}$ with codes C01-C02, C03, C04 and $\mathrm{C} 05-\mathrm{C} 06$. SRs related to head and neck cancer (C00-C14) with cases of oral cancer were included (as long as at least $50 \%$ of the participants had oral cavity cancer, or data for this cancer alone were available separately). Included SRs had conducted a comprehensive search in at least two different databases and reported the assessment of risks of bias or quality of their included studies. ${ }^{6}$ When several articles published by the same team were identified, we considered the most recent publication. Conversely, SRs about prognosis, safety or cost-effectiveness were excluded.

\section{Search strategy}

We searched for systematic literature in MEDLINE (via PubMed), EMBASE (via Ovid), Epistemonikos, The Cochrane Database of Systematic Reviews (via The Cochrane Library) and Database of Abstracts of Reviews of Effects and Health Technology Assessments (via The Cochrane Library). The latest search was conducted on October 25, 2018.

We used MeSH descriptor and free text terms for oral cavity cancer, such as "mouth neoplasms", "oral carcinoma", "oral cancer", "oral tumor", "buccal carcinoma", and thesaurus terms when available. We adapted the search strategy in accordance with the specific characteristics of each database (Supplementary material 1) with no language restrictions. In addition, a cited reference search was conducted.

\section{SR selection}

We managed all retrieved titles and abstracts with the reference manager software EndNote ${ }^{\circledR}$ (Version X7, Thomson Reuters). After removing duplicates, two reviewers (MMA and JVAF) independently screened all titles/abstracts to exclude irrelevant studies. Then, full articles were obtained for a final decision. Detailed reasons for exclusion of any study considered relevant were clearly stated.

\section{Methodological quality assessment}

The report of methodological quality for each SR was assessed with the Assessing the Methodological Quality of Systematic Reviews (AMSTAR)-2 tool, a validated 16-item instrument for critically appraising SRs. ${ }^{14}$ It has an overall rating based on weaknesses in critical domains (items: 2, 4, 7, 9, 11, 13 and 15). Briefly, the overall confidence in the results of the SR is rated in the following four categories: "High", no or one non-critical weakness; 
"Moderate", more than one non-critical weakness; "Low", one critical flaw with or without non-critical weaknesses and "Critically low", more than one critical flaw with or without non-critical weaknesses.

\section{Data extraction}

General characteristics of the SR: authors, publication year, type of SR (with or without meta-analysis), objective, search date, design and number of included studies, and number of included participants.

Characteristics of research questions: we identified the research questions of each SR based on the aims stated by the authors, the eligibility criteria and the conclusions of the SR. The research questions were drawn using the PICO framework, which specifies the four key components of a well-defined therapeutic question: population, intervention, comparison and outcomes. ${ }^{6}$ A research question was considered if all the elements of the PICO framework were provided and a conclusion about the direction of the effect was described anywhere in the SR. We extracted details on the population characteristics (eg, adult population, type of cancer, stage and cancer location), the intervention and comparator (eg, type of intervention and comparison broadly categorized as chemotherapy, surgery, radiotherapy, immunotherapy and targeted therapy) and the outcomes.

The conclusions of the SR authors were classified into five categories following previously reported criteria. ${ }^{12}$ Briefly, the "beneficial" category was used if there were conclusions with evidence of a positive effect and SR authors used a language clearly indicative of a beneficial effect without major concerns regarding the existing evidence. The "probably beneficial" category was used for those conclusions where the evidence base was insufficient to draw firm conclusions despite the positive treatment effect and the reporting suggested a benefit. The "harmful" category was used when the reporting of the conclusions was clearly indicative of a harmful effect. The "no differential effect" category was used for conclusions that provided evidence for no difference between the intervention and the comparator. Finally, the "inconclusive" category was used if the direction of results was different across or within reviews due to conflicting results or limitations of individual studies.

Two authors (MMA and JVAF) independently performed all processes of study selection, methodological quality assessment and data extraction. If there were any disagreements, these were resolved by consensus, and when necessary, an additional reviewer (GUC) participated in the discussion until an agreement was reached. If needed, we contacted the SR authors for clarification or to obtain missing information.

\section{Evidence mapping presentation}

We presented the evidence mapping on tables describing the characteristics of the included SRs and on other tables providing the characteristics of all identified PICOs. We performed a narrative description of the PICOs stratified by disease severity (resectable and nonresectable cancers). In addition, we designed a bubble plot where each bubble represents one SR. This chart displays information in three dimensions: 1) the rating of authors' conclusions represented in the $\mathrm{x}$-axis as "beneficial", "probably beneficial", "harmful", "no differential effect" and "inconclusive"; 2) AMSTAR-2 assessment in $y$-axis and 3) the number of primary studies included in the $\mathrm{SR}$, which is shown in each bubble and is represented by the bubble size. Each bubble also represents a pie showing the proportion of randomized controlled trials (RCTs) included using a black bold line.

\section{Results Studies selected}

The research yielded 2,547 records after removing duplicates. After title and abstract screening, 127 articles were obtained for final full-text review; $15 \mathrm{SRs}^{15-29}$ met the eligibility criteria (Figure 1). The list of excluded studies along with exclusion rationale is available in Supplementary material 2.

\section{Characteristics of the included SRs}

Thirteen SRs ${ }^{15,16,18-27,29}$ included a meta-analysis, and all SRs ${ }^{15-29}$ were published in English between 2010 and 2018. Nine SRs ${ }^{15,19,22-26,28,29}$ had focused on oral cavity cancer exclusively, whereas other six SRs ${ }^{16-18,20,21,27}$ had focused on head and neck cancers, with the oropharyngeal cancer being the most frequent among them. Eight SRs ${ }^{15,17,19,22,24,27-29}$ assessed surgical interventions, three $\mathrm{SRs}^{16,21,25}$ assessed radiotherapy, three $\mathrm{SRs}^{20,23,26}$ assessed chemotherapy and one $\mathrm{SR}^{18}$ assessed targeted therapy and immunotherapy. SRs included primary studies conducted from 1969 to 2015; the number of patients included in each SR ranged from 309 to 16,767 adult individuals. This evidence mapping included 118 reports of primary studies (Supplementary material 3) with 10,423 participants after considering the overlapping or duplication of studies. These studies included 65 (55.1\%) RCTs ( $\mathrm{n}=5,724), 48(40.7 \%)$ observational studies $(n=42,396)$ and $5(4.2 \%)$ controlled clinical trials $(n=460)$. Table 1 shows the characteristics of included SRs. 


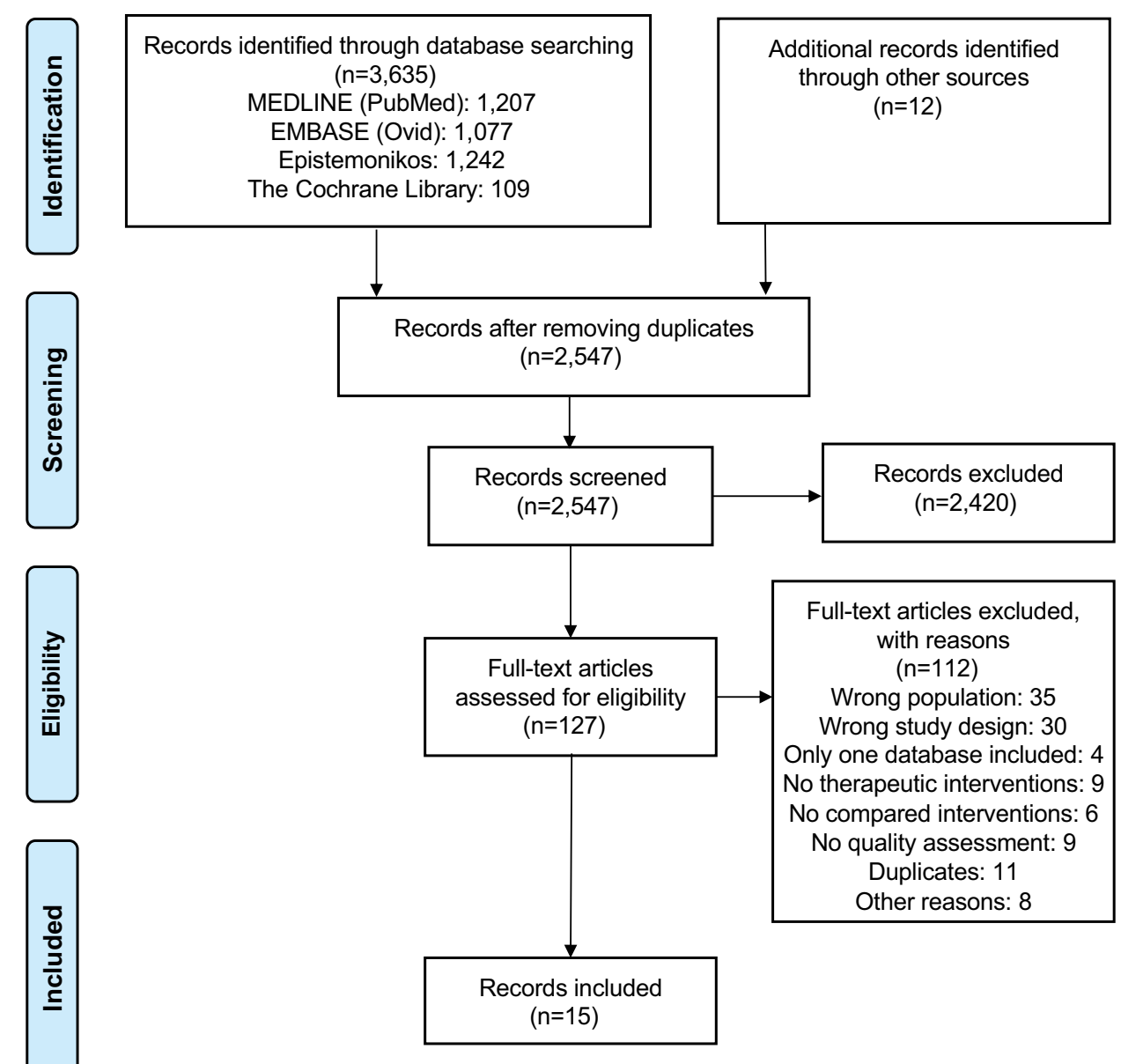

Figure I PRISMA flow diagram detailing the selection process.

\section{The methodological quality of SRs}

Ten SRs ${ }^{15,19,22-29}$ scored "Critically low", three SRs ${ }^{16,20,21}$ scored "Low" and only two SRs ${ }^{17,18}$ scored "High" methodological quality, according to the AMSTAR-2 critical appraisal criteria (Figure 2). The SRs were downgraded mainly because the SR authors did not explain their selection of the study designs for inclusion in the review, ${ }^{16-23,25-29}$ sources of funding for the included studies were not clearly stated, ${ }^{15,16,19,22-29}$ there was no reference to a protocol, ${ }^{15,19,22-29}$ and the list of excluded studies was not provided. ${ }^{15,19,22,24-27,29}$

\section{Characteristics of PICOs from SRs}

The evidence mapping of the therapeutic interventions for oral cancer is presented in Figure 3; 30 PICOs were extracted, which focused on two population groups: patients with resectable oral cancers and patients with unresectable cancer.

\section{Patients with resectable oral cancers}

Thirteen SRs ${ }^{15,17-24,26-29}$ were conducted including 18 PICOs. Eight PICOs evaluated surgical interventions, ${ }^{17,19,22,24,27-29}$ five PICOs assessed chemotherapy, ${ }^{20,23,26}$ three PICOs assessed radiotherapy ${ }^{17,21}$ and two PICOs assessed immunotherapy. ${ }^{18}$
Eight PICOs were reported as "beneficial", one PICO as "probably beneficial", eight PICOs as "no differential effect" and one PICO was reported as "inconclusive" (Table 2).

Interventions reported as "beneficial" were as follows: 1) the elective neck dissection was better than no elective neck dissection in patients with negative neck nodes in terms of cervical metastasis rate, overall 5-year survival rate and occult cervical metastasis; ${ }^{28}$ 2) the incontinuity neck dissection was better than discontinuous neck dissection in terms of local recurrence; $\left.{ }^{29} 3\right)$ a wider pathological margin $(\geq 5 \mathrm{~mm})$ was better than a narrow pathological margin $(<5 \mathrm{~mm})$ in terms of local recurrence rates in patients with oral squamous cell carcinoma treated by primary surgery without adjuvant therapy; ${ }^{15} 4$ ) radiotherapy combined with surgery was better than radiotherapy alone in terms of total mortality; ${ }^{17} 5$ ) the use of intra-arterial bleomycin and vincristine combined with surgery was better than surgery alone in terms of overall survival; ${ }^{20} 6$ ) post-surgery chemotherapy using methotrexate as chemotherapy drug was better than surgery alone in terms of total mortality; ${ }^{20} 7$ ) induction chemotherapy followed by surgery with or without radiotherapy was better than surgery with or without radiotherapy in patients with positive 
Table I Characteristics of the included SRs

\begin{tabular}{|c|c|c|c|c|c|c|}
\hline $\begin{array}{l}\text { Author } \\
\text { and year }\end{array}$ & $\begin{array}{l}\text { Study } \\
\text { design }\end{array}$ & $\begin{array}{l}\text { Search } \\
\text { date }\end{array}$ & Objective & $\begin{array}{l}\text { Design and } \\
\text { number of } \\
\text { included } \\
\text { studies }\end{array}$ & $\begin{array}{l}\text { Participants } \\
\text { (n) }\end{array}$ & $\begin{array}{l}\text { AMSTAR-2 } \\
\text { score }\end{array}$ \\
\hline $\begin{array}{l}\text { Anderson } \\
\text { et al, } \\
2015^{15}\end{array}$ & SRM & Not given & $\begin{array}{l}\text { To determine whether a wider pathological } \\
\text { margin reduces local recurrence rates in } \\
\text { patients with OSCC treated by primary surgery } \\
\text { without adjuvant therapy }\end{array}$ & Cohort: 5 & 539 & Critically low \\
\hline $\begin{array}{l}\text { Baujat et } \\
\text { al, } 2010^{16}\end{array}$ & SRM & $\begin{array}{l}\text { August } \\
2010\end{array}$ & $\begin{array}{l}\text { To study the effects of altered fractionation } \\
\text { radiotherapy vs conventional radiotherapy on } \\
\text { overall survival rates }\end{array}$ & RCT: 15 & 6,515 & Low \\
\hline $\begin{array}{l}\text { Bessell et } \\
\text { al, 201 }{ }^{17}\end{array}$ & SR & $\begin{array}{l}\text { February } \\
2011\end{array}$ & $\begin{array}{l}\text { To determine which surgical treatment } \\
\text { modalities for oral cavity and oropharyngeal } \\
\text { cancers result in increased overall survival, } \\
\text { disease-free survival, progression-free survival } \\
\text { and reduced recurrence }\end{array}$ & RCT: 7 & 669 & High \\
\hline $\begin{array}{l}\text { Chan et al, } \\
2015^{18}\end{array}$ & SRM & $\begin{array}{l}\text { February } \\
2015\end{array}$ & $\begin{array}{l}\text { To assess the effects of molecularly targeted } \\
\text { therapies and immunotherapies, in addition to } \\
\text { standard therapies, for the treatment of oral } \\
\text { cavity or oropharyngeal cancers }\end{array}$ & RCT: 12 & 2,488 & High \\
\hline $\begin{array}{l}\text { Ding et al, } \\
2018^{19}\end{array}$ & SRM & $\begin{array}{l}\text { November- } \\
\text { December } \\
2017\end{array}$ & $\begin{array}{l}\text { To compare elective neck dissection with } \\
\text { observation or therapeutic neck dissection } \\
\text { specifically in patients with early-stage OSCC } \\
\text { and clinically NO neck to explore the potential } \\
\text { benefits of elective neck dissection }\end{array}$ & $\begin{array}{l}\text { RCT: } 5 \\
\text { Case- } \\
\text { control: I }\end{array}$ & 865 & Critically low \\
\hline $\begin{array}{l}\text { Furness et } \\
\text { al, } 201 \mathrm{I}^{20}\end{array}$ & SRM & $\begin{array}{l}\text { December } \\
2010\end{array}$ & $\begin{array}{l}\text { To determine whether chemotherapy, in } \\
\text { addition to radiotherapy and/or surgery for } \\
\text { oral cavity and oropharyngeal cancer, results in } \\
\text { increased overall survival, disease-free survival, } \\
\text { progression-free survival, locoregional control } \\
\text { and reduced recurrence }\end{array}$ & RCT: 89 & 16,767 & Low \\
\hline $\begin{array}{l}\text { Glenny et } \\
\text { al, } 2010^{21}\end{array}$ & SRM & July 2010 & $\begin{array}{l}\text { To determine which radiotherapy regimens for } \\
\text { oral cavity and oropharyngeal cancers result in } \\
\text { increased overall survival, disease-free survival, } \\
\text { progression-free survival and locoregional } \\
\text { control }\end{array}$ & RCT: 30 & 6,536 & Low \\
\hline $\begin{array}{l}\text { Gou et al, } \\
2018^{22}\end{array}$ & SRM & May 2016 & $\begin{array}{l}\text { To explore the survival rate and disease control } \\
\text { in patients with histological evidence of bone } \\
\text { invasion and to compare the differences in } \\
\text { survival rate and disease control between } \\
\text { patients who underwent marginal mandibular } \\
\text { resection and those who underwent segmental } \\
\text { mandibulectomy }\end{array}$ & Cohort: 15 & 1,672 & Critically low \\
\hline $\begin{array}{l}\text { Lau et al, } \\
2016^{23}\end{array}$ & SRM & March 2016 & $\begin{array}{l}\text { To analyze the effect of induction } \\
\text { chemotherapy in OSCC treatment by } \\
\text { performing an updated SR and cumulative } \\
\text { meta-analysis }\end{array}$ & RCT: 27 & 2,872 & Critically low \\
\hline $\begin{array}{l}\text { Liang et al, } \\
2015^{24}\end{array}$ & SRM & April 2015 & $\begin{array}{l}\text { To access the feasibility of selective neck } \\
\text { dissection in oral cancer patients with positive } \\
\text { neck nodes }\end{array}$ & Cohort: 5 & 443 & Critically low \\
\hline $\begin{array}{l}\text { Liu et al, } \\
2013^{25}\end{array}$ & SRM & June 2012 & $\begin{array}{l}\text { To compare the efficacy and safety of high- } \\
\text { dose rate and low-dose rate brachytherapy in } \\
\text { treating early-stage oral cancer }\end{array}$ & $\begin{array}{l}\text { RCT: I } \\
\text { Controlled } \\
\text { trial: } 5\end{array}$ & 607 & Critically low \\
\hline $\begin{array}{l}\text { Marta et } \\
\text { al, } 2015^{26}\end{array}$ & SRM & $\begin{array}{l}\text { January } \\
2015\end{array}$ & $\begin{array}{l}\text { To assess the effectiveness and safety of } \\
\text { induction chemotherapy prior to surgery for } \\
\text { untreated OSCC patients }\end{array}$ & RCT: 2 & 451 & Critically low \\
\hline
\end{tabular}

(continued) 
Table I (continued)

\begin{tabular}{|c|c|c|c|c|c|c|}
\hline $\begin{array}{l}\text { Author } \\
\text { and year }\end{array}$ & $\begin{array}{l}\text { Study } \\
\text { design }\end{array}$ & $\begin{array}{l}\text { Search } \\
\text { date }\end{array}$ & Objective & $\begin{array}{l}\text { Design and } \\
\text { number of } \\
\text { included } \\
\text { studies }\end{array}$ & $\begin{array}{l}\text { Participants } \\
\text { (n) }\end{array}$ & $\begin{array}{l}\text { AMSTAR-2 } \\
\text { score }\end{array}$ \\
\hline $\begin{array}{l}\text { Pang et al, } \\
2016^{27}\end{array}$ & SRM & $\begin{array}{l}\text { September } \\
2016\end{array}$ & $\begin{array}{l}\text { To compare the prognoses outcomes } \\
\text { of mandibular preservation method and } \\
\text { the mandibulotomy approach in oral and } \\
\text { oropharyngeal cancer patients }\end{array}$ & Cohort: 6 & 309 & Critically low \\
\hline $\begin{array}{l}\text { Tang and } \\
\text { Leung, 2016 }\end{array}$ & SR & February 2015 & $\begin{array}{l}\text { To answer the clinical question, "When should } \\
\text { elective neck dissection be performed in maxillary } \\
\text { gingival and alveolar squamous cell carcinoma with } \\
\text { negative neck nodes?" }\end{array}$ & Cohort: 10 & 506 & Critically low \\
\hline $\begin{array}{l}\text { Wang et al, } \\
2018^{29}\end{array}$ & SRM & March 2017 & $\begin{array}{l}\text { To perform a meta-analysis to compare } \\
\text { discontinuous neck dissection with incontinuity } \\
\text { neck dissection as a treatment modality for SCC of } \\
\text { the tongue and floor of the mouth }\end{array}$ & Cohort: 8 & 796 & Critically low \\
\hline
\end{tabular}

Abbreviations: AMSTAR-2, Assessing the Methodological Quality of Systematic Reviews-2; OSCC, oral squamous cell carcinoma; RCT, randomized controlled trial; SCC, squamous cell carcinoma; SR, systematic review; SRM: systematic review with meta-analysis.

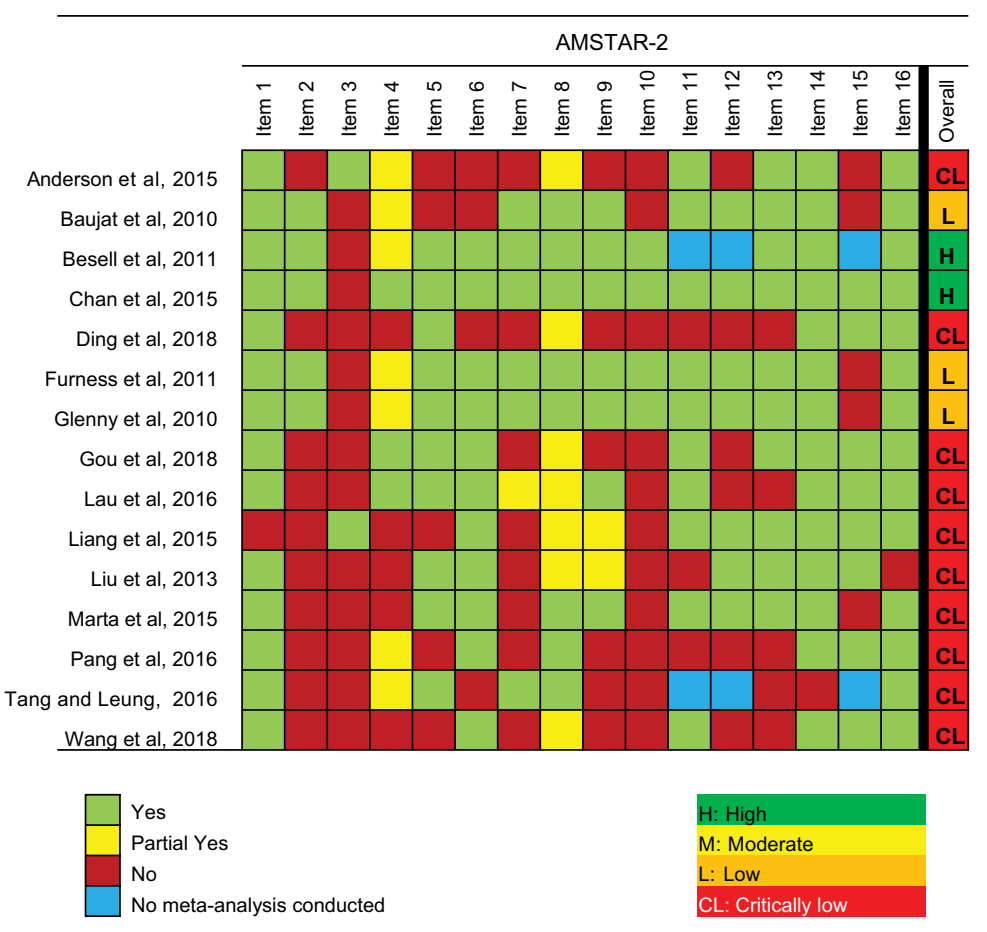

Items

$\frac{1 \text { Did }}{1 .}$ the research questions and inclusion criteria for the review include the components of PICO?

2. Did the report of the review contain an explicit statement that the review methods were established prior to the conduct of their review, and did the report justify any significant deviations from the protocol?*

3 . Did the review authors explain their selection of the study designs for inclusion in the review?

inclusion in the review?
4 . Did the review authors use a comprehensive literature search strategy?*

5 . Did the review authors perform study selection in duplicate?

6. Did the review authors perform data extraction in duplicate?

7. Did the review authors provide a list of excluded studies and justify the exclusions?*

8. Did the review authors describe the included studies in adequate detail?

9. Did the review authors use a satisfactory technique for assessing the risk of bias (RoB) in individual studies that were included in the review?* 10. Did the review authors report on the sources of funding for the studies included in the review?

11. If meta-analysis was performed, did the review authors use appropriate methods for statistical combination of results?*

12. If meta-analysis was performed, did the review authors assess the potential impact of RoB in individual studies on the results of the metaanalysis or other evidence synthesis?

13. Did the review authors account for RoB in individual studies when interpreting/discussing the results of the review?*

14. Did the review authors provide a satisfactory explanation for, and discussion of, any heterogeneity observed in the results of the review?

15. If they performed quantitative synthesis, did the review authors carry out an adequate investigation of publication bias (small study bias) and discuss its likely impact on the results of the review?*

16 . Did the review authors report any potential sources of conflict of interest, including any funding they received for conducting the review?

${ }^{\star}$ Critical domain

Figure 2 Methodological quality of the included systematic reviews.

Abbreviation: AMSTAR-2, Assesing the Methodological Quality of Systematic Reviews-2; PICO, Population-Intervention-Comparison-Outcome.

nodules classified as level II, in terms of overall survival ${ }^{26}$ and 8 ) the use of recombinant interleukin-2 plus surgery was better than surgery alone in terms of overall survival. ${ }^{18}$

\section{Patients with unresectable cancer}

Six SRs ${ }^{16,18,20,21,23,25}$ were conducted including 12 PICOs. Nine PICOs assessed chemotherapy, ${ }^{20,23}$ two PICOs assessed radiotherapy ${ }^{16,21,25}$ and one PICO assessed targeted therapy. ${ }^{18}$
Two PICOs were reported as "beneficial", two PICOs as "probably beneficial" and eight PICOs were reported as "no differential effect" (Table 3).

The interventions reported as "beneficial" were: 1) altered fractionation radiotherapy was better than conventional radiotherapy in terms of overall survival ${ }^{16}$ and 2) bleomycin was better than methotrexate in terms of tumor regression. ${ }^{20}$ 
A

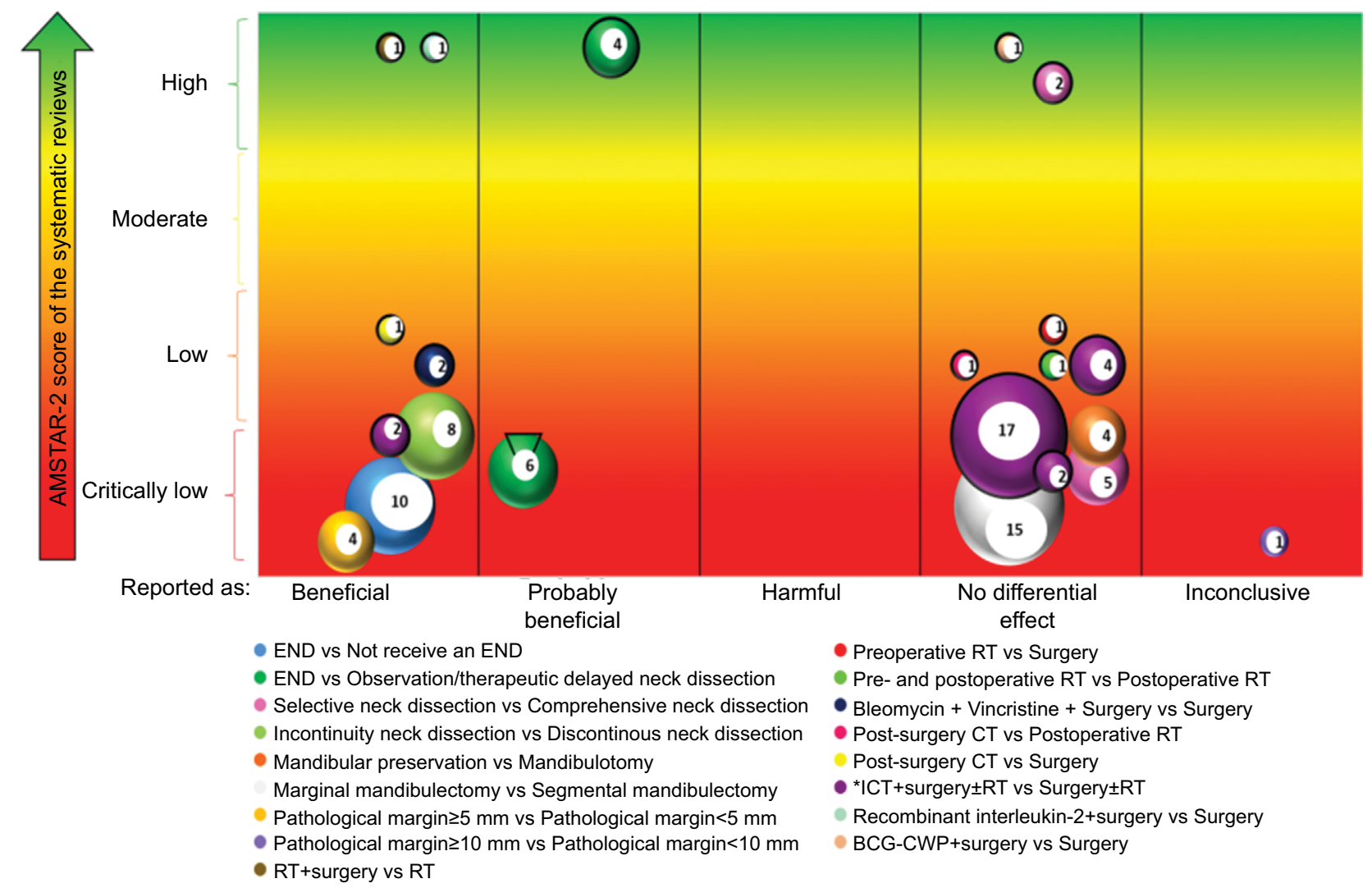

B

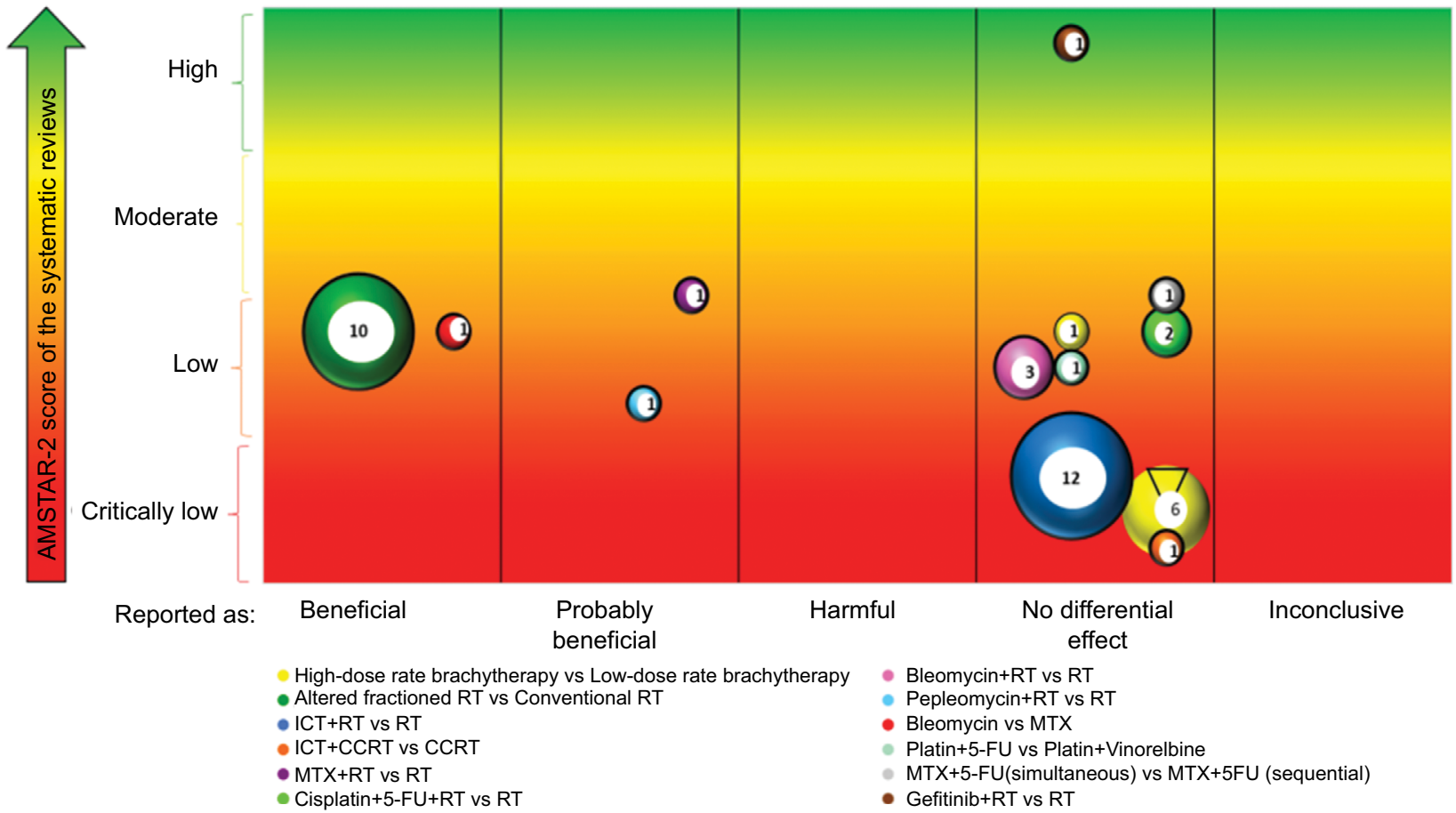

Figure 3 Evidence mapping of the therapeutic interventions for oral cancer.

Notes: (A) Interventions for resectable oral cancer. (B) Interventions for unresectable oral cancer. Bubble plots where each bubble represents one SR. The number of individual studies included in the SR is shown in each bubble and is represented by the bubble size. Each bubble also represents a pie showing the proportion of randomized controlled trials included with a black bold line. *Two PICOs included this comparison, but the intervention was reported as "beneficial" only in the PICO for patients with positive neck nodes level II. The number of individual studies included in the SR is shown in each bubble and is represented by the bubble size.

Abbreviations: 5-FU, 5-fluorouracil; BCG-CWP, Bacillus Calmette-Guérin-cell wall preparation; CCRT, concomitant chemo-radiotherapy; CT, chemotherapy; END, elective neck dissection; ICT, induction chemotherapy; MTX, methotrexate; PICO, Population-Intervention-Comparison-Outcome; RT, radiotherapy; SR, systematic review. 


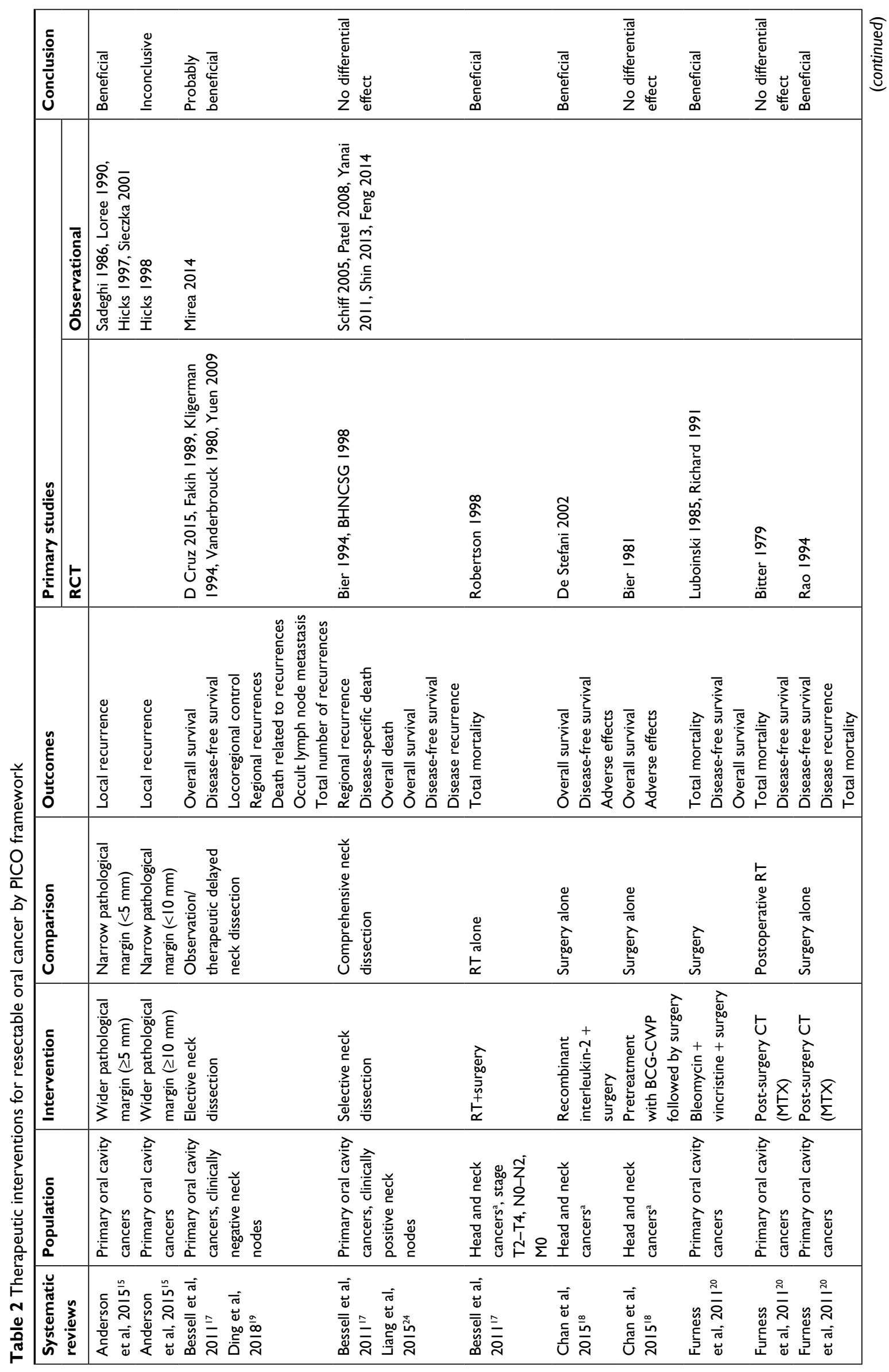


Dovepress

Evidence mapping on treatments for oral cancer

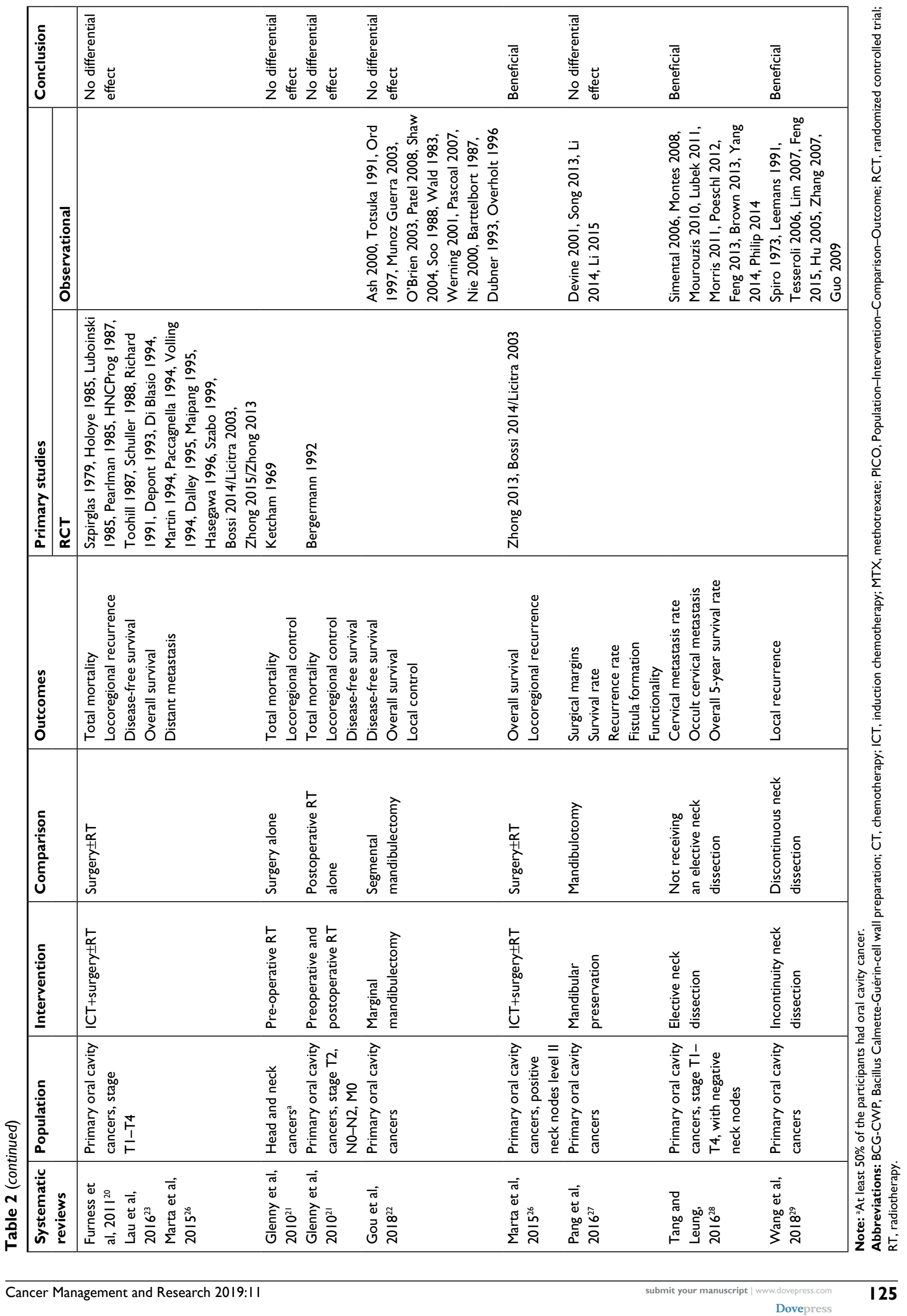




\section{Discussion}

Evidence mapping is a relatively new tool used to summarize available scientific evidence about a specific topic. However, although there is no standard definition of it or consensus about its components or the methods to be used, there are common characteristics for these types of review. ${ }^{7}$ In general, it includes a systematic search covering a broad field to identify gaps in knowledge and/or future research needs. It also presents results in a user-friendly format, often a visual figure or graph, or a searchable database. ${ }^{7}$ Evidence mapping can produce an extensive list of prioritized research questions in a topic area, even in the absence of study retrieval and data extraction. It is a potential springboard for research, policy development and research funding. ${ }^{9}$

This evidence mapping may be the first one about therapeutic interventions for oral cancer because we found no previous reports. We decided to use this methodology developed by GEM initiative since it is rational and systematic. ${ }^{9}$ Recently, a report stated that most of the documents that met the common characteristics of evidence mapping referenced this methodology. ${ }^{7}$ The referenced methodology includes three core tasks: setting the boundaries and context of the topic area in question, searching and selecting relevant studies and reporting on search results and study characteristics. ${ }^{9}$ Moreover, we added two uncommon components in evidence mapping, which were previously reported: the methodological quality assessment of SRs and the classification of the conclusions as beneficial, probably beneficial, no differential effect, inconclusive or harmful according to the results reported by authors. ${ }^{12}$ It has been suggested that this approach allows locating the results of one study in relation to other studies with the same comparison on a bubble plot, obtaining a broader outlook of the available evidence and its quality. ${ }^{12}$

The results of this evidence mapping show that in line with available evidence, there is a sprinkling of SRs about therapeutic interventions for oral cancer, since only 15 SRs focusing on different therapies met the criteria. Moreover, most SRs included a small number of primary studies; thus, it may suggest that the evidence of this issue is limited. However, we wish to highlight that most of the primary studies included in this evidence mapping were RCTs, which is an aspect with clinical relevance because experimental studies are the best design to evaluate the efficacy of new therapeutic options. ${ }^{30}$ We also highlight that no comparison was reported as "harmful", which is probably because most RCTs with negative conclusions are seldom published. ${ }^{31}$

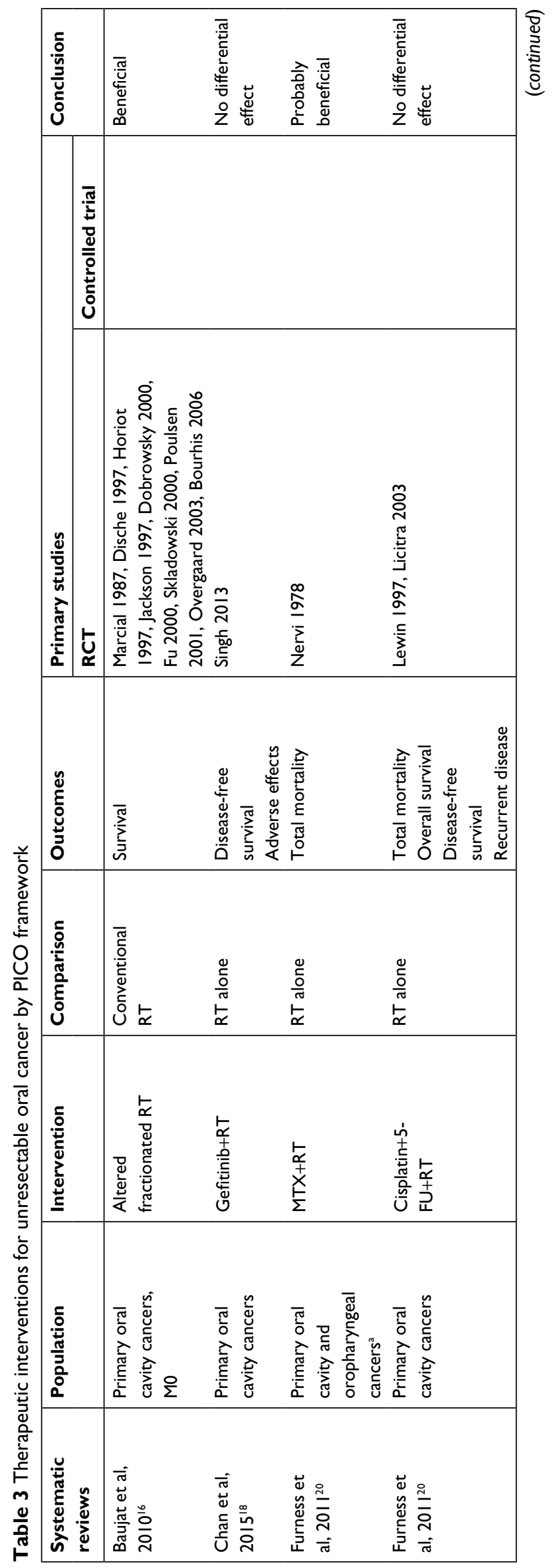



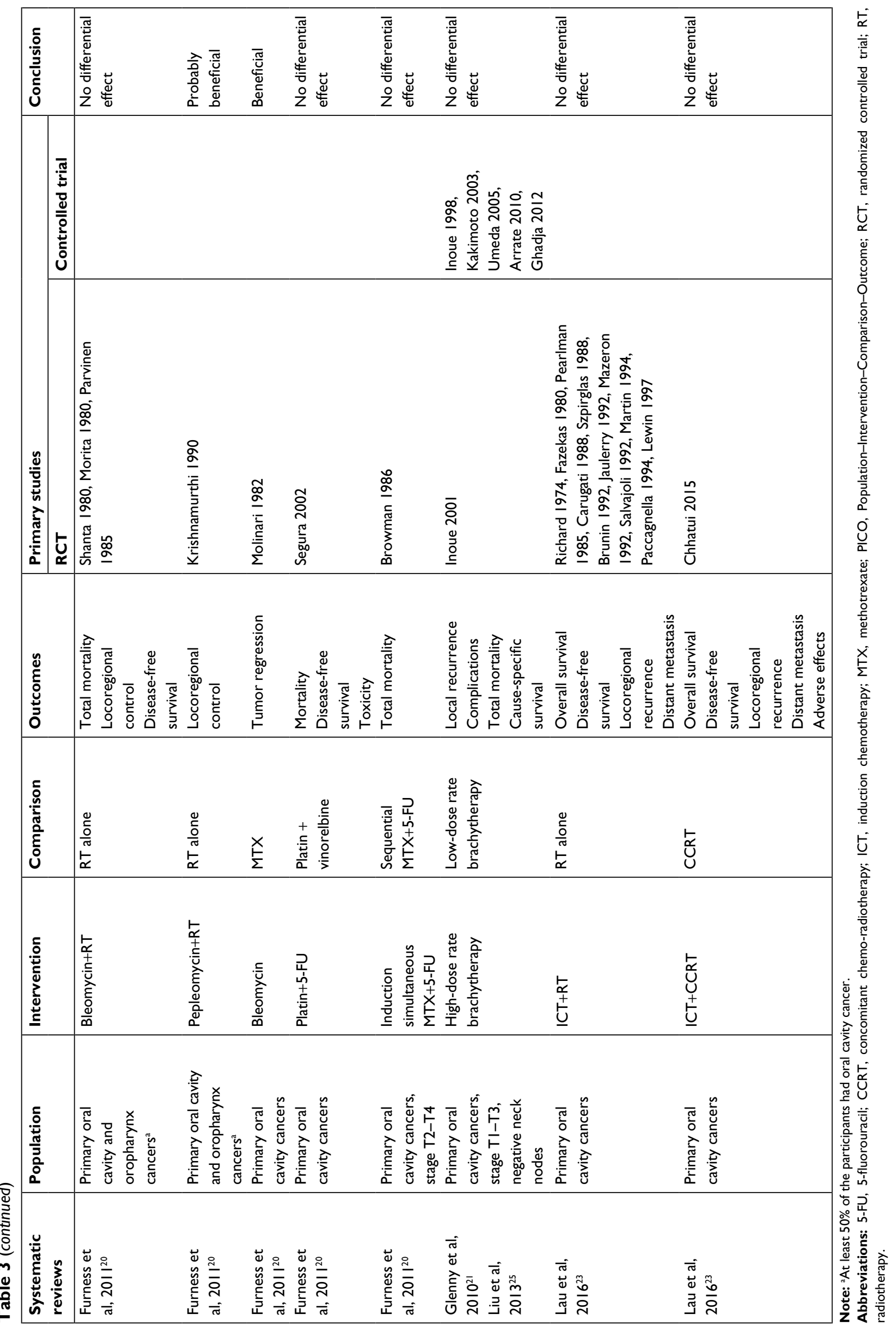
According to methodological quality assessment, most of the SRs scored "Critically low" methodology quality with the AMSTAR-2 tool. This indicates that there is room for a potential improvement of the quality of SRs in this field. Among the domains to improve are the inclusion of an explicit statement indicating that the SR methods were established prior to the conduct of the SR, as well as the inclusion of a report justifying any significant deviations from the protocol; the explanation of the selection of the study designs for inclusion in the SR; the provision of the list of excluded studies and justifying the exclusions; and the reporting of the conflicts of interests, indicating the source of funding or support for each of the included studies. Although the methodological quality assessment is not a core task of an evidence mapping, it has been suggested that any type of review should include this process in order to evaluate the consistency of its conclusions. ${ }^{6,12}$

In this evidence mapping, the main therapeutic interventions reported by the authors as beneficial for patients with resectable oral cancer are surgery alone or in combination with radiotherapy or chemotherapy, depending on the extent of the disease. These results were based on SRs ${ }^{15,17,18,20,26,28,29}$ with "Critically low" to "High" methodological quality evaluated with AMSTAR-2 tool. However, these reports should be taken with caution because some SRs ${ }^{15,28,29}$ only included observational studies. Moreover, despite the fact that some interventions reported by the authors as "beneficial" were based on RCTs, ${ }^{32-39}$ the majority of these comparisons included just one RCT, ${ }^{32,35,36}$ some of which had a small sample size.

There were fewer comparisons for patients with unresectable oral cancer than for those with resectable oral cancer. Only two interventions were reported by the authors as beneficial; these found altered fractionated radiotherapy to be superior to other forms of radiotherapy ${ }^{16}$ and to the use of bleomycin as a chemotherapy drug. ${ }^{20}$ We wish to emphasize that all comparisons for this population were based on SRs ${ }^{16,18,20,21,23,25}$ including only RCTs and controlled clinical trials. Nevertheless, these results should be placed in context. Firstly, despite the fact that altered fractionated radiotherapy was reported as a beneficial treatment for oral cancer, there is a previous report ${ }^{40}$ of the same $\mathrm{SR}^{16}$ that shows the same outcomes, but there are some numeric inconsistencies in the results between these reports, even though the same authors included the same studies in the analysis. For these reasons, we contacted the authors and they clarified that the latest report had probably reclassified patients and provided the most accurate estimates. Secondly, recommending the use of bleomycin was based on only one single $\mathrm{RCT}^{41}$ published long time ago. Thus, nowadays, it is likely that there are other options for chemotherapy. For example, 5-fluorouracil, cisplatin, carboplatin, paclitaxel and docetaxel are among the chemotherapy drugs most often used for oral and oropharyngeal cancers; these may be used alone or combined with other drugs. ${ }^{42,43}$

We were able to identify some research gaps on this topic such as targeted therapy, since just only one $\mathrm{RCT}^{44}$ addressing this topic was included in one SR. ${ }^{18}$ Moreover, despite a sharp increase in research into molecularly targeted therapies and a rapid expansion in the number of trials assessing new targeted therapies, their value for treating oral cancers remains unclear. The advantage that these therapies may have over conventional chemotherapy is that rather than affecting both healthy and cancerous cells, they target only cancer cells. ${ }^{18}$ Recently, de Felice and Guerrero Urbano ${ }^{45}$ reviewed the published clinical trials about a specific targeted therapy and suggested that it could become a "central player" in head and neck cancers as it offers a potential therapeutic opportunity. Likewise, the same authors claimed that despite the ongoing trials, clinical data are lacking.

This evidence mapping can be used to help with the interpretation of published research syntheses, such as SRs and meta-analyses, and it can also be used as a tool to engage stakeholders. Similarly, it can be used to address future research projects focused on knowledge gaps identified with this evidence mapping, as well as to conduct SRs and RCTs focused on new therapeutic interventions for oral cancer. It is useful to clarify that this evidence mapping does not intend to replace any clinical protocol or guideline. Its aim is to describe the available evidence on therapeutic interventions for oral cancers; thus, any recommendations and practice points should be considered in the context of clinical judgment for each patient, the available alternatives and their risk/benefit ratio, the available resources and other contextual factors. ${ }^{46}$

Among the strengths of this study, we highlight that a sensitive search strategy was performed, so it is unlikely that any relevant studies were missed. Likewise, two reviewers independently conducted the whole processes of selection, methodological quality assessment and data extraction from the included SRs. All these processes provide reasonable confidence in these results.

Certain limitations in this evidence mapping should be taken into account. Firstly, there were limited SRs comparing therapeutic interventions for oral cancer, and 
some of them included only observational studies; thus, some bias due to confounding factor may exist in these studies. Secondly, since some SRs had methodological limitations, their conclusions can be subject to bias; therefore, their conclusions regarding the effectiveness of the different interventions could be invalid. However, this is thoroughly reported in our results, so each conclusion can be assessed by the reader including its limitation. Other limitation is the language barrier; all the included SRs were published in English, which eliminated the inclusion into this mapping of available evidence published in any other language.

\section{Conclusion}

There is limited available evidence about therapeutic interventions for oral cancer. The methodological quality of most included SRs in this mapping scored "Critically low" quality with AMSTAR-2 tool. The main beneficial therapeutic interventions reported by authors for patients with resectable oral cancer are surgery alone or in combination with radiotherapy or chemotherapy. Evidence for the benefits of treatments for unresectable oral cancer is lacking. These findings highlight the need to address future research focused on new therapeutic interventions and knowledge gaps in this field, as well as increased efforts are required to improve the methodology quality and reporting process of SRs on treatments for oral cancer. The evidence mapping is an adequate and reliable methodology to identify the current available evidence about therapeutic interventions.

\section{Data sharing statement}

All data generated or analyzed during this study are included in this published article and its Supplementary materials.

\section{Acknowledgments}

The authors thank Andrea Cervera Alepuz for proofreading this manuscript. This work was presented as a poster at the 95th General Session \& Exhibition of the International Association for Dental Research-IADR 2017, San Francisco, USA.

\section{Author contributions}

XBC, GUC, MMA and MB conceived the study. MMA, $\mathrm{MB}, \mathrm{XBC}, \mathrm{GUC}, \mathrm{JVAF}$ and IS designed the study. MMA and JVAF analyzed the data. MMA and JVAF wrote the first draft of the manuscript. MMA, JVAF, MB and XBC contributed to the writing of the manuscript. All authors contributed toward data analysis, drafting and revising the paper, gave final approval of the version to be published and agree to be accountable for all aspects of the work.

\section{Disclosure}

MMA received financial support from the "Bolivar Gana con Ciencia" Fellowship Program. This author is a Ph.D candidate at the Methodology of Biomedical Research and Public Health program, Universitat Autònoma de Barcelona. The authors report no other conflicts of interest in this work.

\section{References}

1. Siegel RL, Miller KD, Jemal A. Cancer statistics, 2017. CA Cancer J Clin. 2017;67(1):7-30.

2. Johnson NW, Warnakulasuriya S, Gupta PC, et al. Global oral health inequalities in incidence and outcomes for oral cancer: causes and solutions. Adv Dent Res. 2011;23(2):237-246.

3. Weatherspoon DJ, Chattopadhyay A, Boroumand S, Garcia I. Oral cavity and oropharyngeal cancer incidence trends and disparities in the United States: 2000-2010. Cancer Epidemiol. 2015;39(4):497-504.

4. Wolff KD, Follmann M, Nast A. The diagnosis and treatment of oral cavity cancer. Dtsch Arztebl Int. 2012;109(48):829-835.

5. Grégoire V, Leroy R, Heus P. Oral Cavity Cancer: Diagnosis, Treatment and Follow-up. Good Clinical Practice (GCP). Brussels: Belgian Health Care Knowledge Centre (KCE). KCE reports 227; 2014.

6. Higgins J, Green S. Cochrane Handbook for Systematic Reviews of Interventions Version 5.1.0 2011. Available from: www.cochrane-handbook. org. 2011.

7. Miake-Lye IM, Hempel S, Shanman R, Shekelle PG. What is an evidence map? A systematic review of published evidence maps and their definitions, methods, and products. Syst Rev. 2016;5:28.

8. Haddaway NR, Bernes C, Jonsson BG, Hedlund K. The benefits of systematic mapping to evidence-based environmental management. Ambio. 2016;45(5):613-620.

9. Bragge P, Clavisi O, Turner T, Tavender E, Collie A, Gruen RL. The global evidence mapping initiative: scoping research in broad topic areas. BMC Med Res Methodol. 2011;11:92.

10. Snilstveit B, Vojtkova M, Bhavsar A, Stevenson J, Gaarder M. Evidence \& gap maps: a tool for promoting evidence informed policy and strategic research agendas. J Clin Epidemiol. 2016;79:120-129.

11. Tricco AC, Lillie E, Zarin W, et al. PRISMA Extension for scoping reviews (PRISMA-ScR): checklist and explanation. Ann Intern Med. 2018;169(7):467.

12. Ballesteros M, Montero N, López-Pousa A, et al. Evidence mapping based on systematic reviews of therapeutic interventions for gastrointestinal stromal tumors (GIST). BMC Med Res Methodol. 2017;17(1):135.

13. WHO. International Classification of Diseases for Oncology. 3rd ed, 1st revision. Geneva: WHO Library Cataloguing-in-Publication Data; 2013.

14. Shea BJ, Reeves BC, Wells G, et al. AMSTAR 2: a critical appraisal tool for systematic reviews that include randomised or non-randomised studies of healthcare interventions, or both. BMJ. 2017;358:j4008.

15. Anderson CR, Sisson K, Moncrieff M. A meta-analysis of margin size and local recurrence in oral squamous cell carcinoma. Oral Oncol. 2015;51(5):464-469.

16. Baujat B, Bourhis J, Blanchard P, et al. Hyperfractionated or accelerated radiotherapy for head and neck cancer. Cochrane Database Syst Rev. 2010;43(1):CD002026.

17. Bessell A, Glenny AM, Furness S, et al. Interventions for the treatment of oral and oropharyngeal cancers: surgical treatment. Cochrane Database Syst Rev. 2011;9(9):CD006205.

18. Chan KK, Glenny AM, Weldon JC, Furness S, Worthington HV, Wakeford H. Interventions for the treatment of oral and oropharyngeal cancers: targeted therapy and immunotherapy. Cochrane Database Syst Rev. 2015;12(12):CD010341.

19. Ding Z, Xiao T, Huang J, et al. Elective neck dissection versus observation in squamous cell carcinoma of oral cavity with clinically N0 neck: a systematic review and meta-analysis of prospective studies. J Oral Maxillofac Surg. 2018. Epub August 22,2018. 
20. Furness S, Glenny AM, Worthington HV, et al. Interventions for the treatment of oral cavity and oropharyngeal cancer: chemotherapy. Cochrane Database Syst Rev. 2011;4(4):CD006386.

21. Glenny A-M, Furness S, Worthington HV, et al. Interventions for the treatment of oral cavity and oropharyngeal cancer: radiotherapy. Cochrane Database Syst Rev. 2010;51(3):CD006387.

22. Gou L, Yang W, Qiao X, et al. Marginal or segmental mandibulectomy: treatment modality selection for oral cancer: a systematic review and meta-analysis. Int J Oral Maxillofac Surg. 2018;47(1):1-10.

23. Lau A, Li KY, Yang WF, Su YX. Induction chemotherapy for squamous cell carcinomas of the oral cavity: a cumulative meta-analysis. Oral Oncol. 2016;61:104-114.

24. Liang L, Zhang T, Kong Q, Liang J, Liao G. A meta-analysis on selective versus comprehensive neck dissection in oral squamous cell carcinoma patients with clinically node-positive neck. Oral Oncol. 2015;51(12):1076-1081.

25. Liu Z, Huang S, Zhang D. High dose rate versus low dose rate brachytherapy for oral cancer - a meta-analysis of clinical trials. PLoS One. 2013;8(6):e65423.

26. Marta GN, Riera R, Bossi P, et al. Induction chemotherapy prior to surgery with or without postoperative radiotherapy for oral cavity cancer patients: systematic review and meta-analysis. Eur J Cancer. 2015;51(17):2596-2603.

27. Pang P, Li RW, Shi JP, et al. A comparison of mandible preservation method and mandibulotomy approach in oral and oropharyngeal cancer: a meta-analysis. Oral Oncol. 2016;63:52-60.

28. Tang L, Leung YY. When should elective neck dissection be performed in maxillary gingival and alveolar squamous cell carcinoma with a cN0 neck? A systematic review. Int J Oral Maxillofac Surg. 2016;45(11):1358-1365.

29. Wang HC, Zheng Y, Pang P, Li RW, Qi ZZ, Sun CF. Discontinuous versus in-continuity neck dissection in squamous cell carcinoma of the tongue and floor of the mouth: comparing the rates of locoregional recurrence. J Oral Maxillofac Surg. 2018;76(5):1123-1132.

30. Sylvester RJ, Canfield SE, Lam TB, et al. Conflict of evidence: resolving discrepancies when findings from randomized controlled trials and meta-analyses disagree. Eur Urol. 2017;71(5):811-819.

31. Jones CW, Handler L, Crowell KE, Keil LG, Weaver MA, Platts-Mills TF. Non-publication of large randomized clinical trials: cross sectional analysis. BMJ. 2013;347:f6104.

32. Robertson AG, Soutar DS, Paul J, et al. Early closure of a randomized trial: surgery and postoperative radiotherapy versus radiotherapy in the management of intra-oral tumours. Clin Oncol. 1998;10(3):155-160.

33. Richard JM, Kramar A, Molinari R, et al. Randomised EORTC head and neck cooperative group trial of preoperative intra-arterial chemotherapy in oral cavity and oropharynx carcinoma. Eur J Cancer. 1991;27(7):821-827.
34. Luboinski B. Preliminary results of a randomized study on preoperative intra-arterial chemotherapy combined with surgery and irradiation for carcinomas of the floor of the mouth. Prog Clin Biol Res. 1985;201:199-203.

35. de Stefani A, Forni G, Ragona R, et al. Improved survival with perilymphatic interleukin 2 in patients with resectable squamous cell carcinoma of the oral cavity and oropharynx. Cancer. 2002;95(1):90-97.

36. Rao RS, Parikh DM, Parikh HK, Bhansali MB, Deshmane VH, Fakih AR. Perioperative chemotherapy in patients with oral cancer. Am J Surg. 1994;168(3):262-267.

37. Zhong LP, Zhang CP, Ren GX, et al. Randomized Phase III trial of induction chemotherapy with docetaxel, cisplatin, and fluorouracil followed by surgery versus up-front surgery in locally advanced resectable oral squamous cell carcinoma. J Clin Oncol. 2013;31(6):744-751.

38. Bossi P, Lo Vullo S, Guzzo M, et al. Preoperative chemotherapy in advanced resectable OCSCC: long-term results of a randomized Phase III trial. Ann Oncol. 2014;25(2):462-466.

39. Licitra L, Grandi C, Guzzo M, et al. Primary chemotherapy in resectable oral cavity squamous cell cancer: a randomized controlled trial. J Clin Oncol. 2003;21(2):327-333.

40. Bourhis J, Overgaard J, Audry H, et al. Hyperfractionated or accelerated radiotherapy in head and neck cancer: a meta-analysis. Lancet. 2006;368(9538):843-854

41. Molinari R, Jortay A, Sancho-Garnier H, et al. A randomized EORTC trial comparing intra-arterial infusion with methotrexate vs bleomycin as initial therapy in carcinoma of the oral cavity. Eur J Cancer Clin Oncol. 1982;18(9):807-812.

42. Srivastava S, Mohammad S, Pant AB, et al. Co-delivery of 5-fluorouracil and curcumin nanohybrid formulations for improved chemotherapy against oral squamous cell carcinoma. J Maxillofac Oral Surg. 2018;17(4):597-610.

43. Noronha V, Joshi A, Patil V, et al. Cisplatin based adjuvant chemoradiation following neoadjuvant chemotherapy and surgery in advanced oral cavity cancers: a deliverable regimen? Indian J Cancer. 2016;53(1):141-142.

44. Singh P, Dixit AK, Prashad SN, Saxena T, Shahoo DP, Sharma D. A randomized trial comparing radiotherapy alone versus radiotherapy with Geftinib in locally advance oral cavity cancer. Clin Cancer Investig J. 2013;2(1):29-33.

45. de Felice F, Guerrero Urbano T. New drug development in head and neck squamous cell carcinoma: the PI3-K inhibitors. Oral Oncol. 2017;67:119-123.

46. Alonso-Coello P, Schünemann HJ, Moberg J, et al. GRADE Evidence to Decision (EtD) frameworks: a systematic and transparent approach to making well informed healthcare choices. 1: introduction. $B M J$. 2016;353:i2016
Cancer Management and Research

\section{Publish your work in this journal}

Cancer Management and Research is an international, peer-reviewed open access journal focusing on cancer research and the optimal use of preventative and integrated treatment interventions to achieve improved outcomes, enhanced survival and quality of life for the cancer patient. The manuscript management system is completely online and includes

\section{Dovepress}

a very quick and fair peer-review system, which is all easy to use. Visit http://www.dovepress.com/testimonials.php to read real quotes from published authors. 